\title{
Analysis of electronic cigarette use among Polish dental students
}

\section{Używanie papierosów elektronicznych przez polskich studentów stomatologii}

\author{
Aida Kusiak ${ }^{1, A, C-F}$, Anna Wojtaszek-Słomińska ${ }^{2, C-F}$, Maria Chomyszyn-Gajewska ${ }^{3, B, C, E}$, Małgorzata Pietruska ${ }^{4, B, E, F}$, Adrian Maj ${ }^{1, B-D}$, \\ Barbara Szkarłat ${ }^{2, B, C}$, Agnieszka Cabała ${ }^{4, B, C}$ \\ 1 Department of Periodontology and Oral Mucosa Diseases, Medical University of Gdańsk, Gdańsk, Poland \\ 2 Department of Orthodontics, Medical University of Gdańsk, Gdańsk, Poland \\ ${ }^{3}$ Department of Periodontology and Oral Medicine, Jagiellonian University Collegium Medicum, Kraków, Poland \\ ${ }^{4}$ Department of Periodontal and Oral Mucosal Diseases, Medical University of Bialystok, Białystok, Poland \\ A - research concept and design; $\mathrm{B}$ - collection and/or assembly of data; $\mathrm{C}$ - data analysis and interpretation; \\ $D$ - writing the article; $E$ - critical revision of the article; $F$ - final approval of article
}

Address for correspondence

Aida Kusiak

E-mail: akusiak@gumed.edu.pl

Funding sources

none declared

Conflict of interest

none declared

Received on June 21, 2017

Revised on August 02, 2017

Accepted on August 28, 2017

DOI

10.17219/dmp/76708

Copyright

○ 2017 by Wroclaw Medical University

and Polish Dental Society

This is an article distributed under the terms of the

Creative Commons Attribution Non-Commercial License

(http://creativecommons.org/licenses/by-nc-nd/4.0/)

\section{Abstract}

Background. E-smoking is a new phenomenon, not only as an opportunity to limit or quit smoking, but it may become an introduction to traditional smoking, especially by young people.

Objectives. The paper reports an analysis of electronic cigarette use among Polish dental students, particularly concerning the reasons for using e-cigarettes.

Material and methods. The research was conducted among 3 medical universities of Poland. The data collection took place between May 2015 and May 2016. There were 581 people (161 men and 420 women) enrolled into the study. All the examined students were 20-25 years old. They were asked to answer 6 questions.

Results A total number of 420 women and 161 men completed the survey form. In the examined group, there were 100 smokers (17.21\%), of which 62 were women, and 38 were men (62 and 38\%, respectively). Among the smokers, 39 people (6.71\% of whole examined population) were smoking traditional cigarettes, 10 students (1.72\%) were smoking e-cigarettes, and 51 people (8.38\%) were smoking both traditional and electronic cigarettes. Among the 39 e-cigarette smokers, there were 26 women and 13 men. The most common time frame when they had begun smoking electronic cigarettes was within less than 6 months. For 28 students (45.9\%), e-smoking was associated with a trend. Next, 18 people (35.29\%) believed that electronic cigarettes would help them quit smoking. The other, rarely-mentioned reasons for using e-cigarettes were: traditional cigarettes' disturbance to the community, lower costs (than traditional cigarettes) and being allowed to use them in public places.

Conclusions. The main reason for taking up electronic cigarettes was the increasing trend. E-smoking is a new phenomenon, and it may become an introduction to traditional smoking, especially by young people.

Key words: epidemiology, electronic cigarettes, e-smoking

Słowa kluczowe: epidemiologia, papieros elektroniczny, e-palenie 
Smoking of electronic cigarettes is a new phenomenon. On one hand, it may constitute an opportunity to limit or quit smoking, but on the other hand it may become an introduction to traditional smoking. The most susceptible groups are young people, and those already addicted to nicotine. ${ }^{1-5}$ To date, it is impossible to assess the advantages of e-smoking and the risk of undesirable effects, and even the toxic influence on oral cavity tissues, ${ }^{6}$ due to the complexity of the phenomenon and an inadequate number of accurate clinical and laboratory studies.

Habitual smokers have the worst clinical results in surgical, nonsurgical and regenerative periodontal treatment. Among the negative influences of nicotine on the periodontium, the following may occur: changes in the subgingival biofilm in the direction of a quantitative and qualitative increase of periopathogens, immunomodulation of the host reaction, e.g. intensification of the destructive processes of the connective tissue and the bone, and deficiency of the healing process. ${ }^{7-9}$ Accordingly, nicotine is considered as the main etiological factor in certain precancer states of the oral cavity mucosa, such as leukoplakia or neoplasms. ${ }^{10-12}$

An important part of prophylactic-therapeutic treatment states minimizing nicotine doses. Nicotine replacement therapy may include patches, tablets or chewing gum containing nicotine. In recent years, attention is focused on so-called electronic cigarettes (e-cigarettes) containing nicotine. ${ }^{13-16}$

According to the World Health Organization, one of the most serious health threats in the world is tobacco smoking. It concerns not only general health problems (including cardiovascular disorders or breathing system disorders), but also oral cavity health (including the periodontal and oral mucosa condition). Habitual smokers have poor clinical results in surgical, nonsurgical, and regenerative periodontal treatment. Among the negative influences of nicotine on the periodontium, the following may occur: unfavorable changes in subgingival biofilm (e.g. quantitative and qualitative increase of periopathogens), immunomodulation of the host reaction (e.g. the intensification of the destructive processes on the connective tissue and the bone), and deficiency of the healing process. ${ }^{7-9}$

In the available literature, there is an insufficient number of studies concerning e-cigarette use among future dentists. This paper reports an analysis of electronic cigarette use among Polish dental students, particularly concerning the reasons for using e-cigarettes.

\section{Material and methods}

the research was conducted among 3 medical universities of Poland: the Medical University of Gdańsk, the Medical University of Bialystok, and Jagiellonian University Collegium Medicum of Cracovia. The data collection took place between May 2015 and May 2016. There were
581 people (161 men and 420 women) enrolled into the study. All the students examined were between 20 and 25 years old. They were asked to answer the questions included in the survey presented below:

1. How long have you been an EC smoker? (0-6 months, 7-12 months, $1-2$ years, $2-3$ years, over 3 years);

2. Did you previously smoke traditional cigarettes? (YES/NO);

3. How long did you or have you been smoking traditional cigarettes? (0-6 months, 7-12 months, 1-2 years, $2-3$ years, $3-5$ years, $5-10$ years, over 10 years);

4. Are you using EC to quit smoking? (YES/NO);

5. Do you have any other reasons for using EC? (YES/NO);

6. Other reasons for using EC (traditional smoking disturbs people nearby, it's cheaper than traditional smoking, can be used in public places).

The study protocol was approved by the Ethics Committee of the Medical University of Gdańsk, Poland (NKBBN/161/2014). The ethical aspects of the research followed the World Medical Association Declaration of Helsinki.

Statistical analysis was performed using Microsoft Office Excel 2007 and STATISTICA v. 10 (StatSoft Polska). A $\chi^{2}$ statistical formula with Yates's correction for continuity was used. Results with a p-level value lower than 0.05 and 0.001 were considered statistically significant.

\section{Results}

The exact numbers and percentage of smokers and nonsmokers are presented in Table 1. A total number of 420 women and 161 men completed the survey form. In the examined group, there were 100 smokers (17.21\%), of which 62 were women and 38 were men $(62$ and 38\%, respectively). Among the smokers, 39 people $(6.71 \%$ of the whole examined population) were smoking traditional cigarettes, 10 students (1.72\%) were smoking e-cigarettes, and 51 people $(8.38 \%)$ were smoking both traditional and electronic cigarettes. In comparison to men, women were smoking both traditional and e-cigarettes more frequently; this result was statistically significant $(\mathrm{p}<0.05)$.

The quantity and percentage of electronic cigarette users in terms of time when smoking started are presented in Table 2. Among the 39 e-cigarette smokers, there were 26 women and 13 men. The most common time frame when they had begun to use electronic cigarettes was within less than 6 months. What is more, the majority in this group (respondents who had started smoking within the last 6 months) were women, and it was statistically significant $(\mathrm{p}<0.05)$.

Table 3 presents the causes of electronic cigarette smoking. For 28 students (45.9\%), e-smoking was associated with a trend. Next, 18 people $(35.29 \%)$ believed that electronic cigarettes would help them quit smoking. The other, rarely-mentioned reasons for using e-cigarettes 
Table 1. Characteristics of study group

\begin{tabular}{|l|c|c|}
\multicolumn{1}{|c|}{ Number and percentage of: } & Females No (\%) & Males No (\%) \\
\hline Non-smokers & $358^{\mathrm{a}}(85.24)$ & $123^{\mathrm{b}}(76.4)$ \\
Smokers traditional cigarettes only & $26(6.19)$ & $13(8.07)$ \\
Smokers electronic cigarettes only & $6(1.43)$ & $4(2.48)$ \\
Smokers traditional and e-cigarettes & $30^{c}(7.14)$ & $21^{\mathrm{d}}(13.04)$ \\
Total & $420(72.29)$ & $10(1.72)$ \\
\hline
\end{tabular}

$p<0.05$ for $a-b, c-d$.

were: traditional cigarettes' disturbance to the community, lower costs (than traditional cigarettes) and being allowed to use them in public places. Compared to men, women more frequently indicated the trend as the main reason for using e-cigarettes; and it was statistically significant $(\mathrm{p}<0.05)$.

\section{Discussion}

The findings presented show that the main reason for e-cigarette smoking is the rising trend. What is more, the plurality of dental students became e-smokers less than 6 months before the survey took place. The study reflects the findings of Callahan-Lyon, ${ }^{2}$ which showed an increase in e-cigarette smoking among not only young adults, but also among children. To date, there is an increasing number of publications concerning the influence of electronic cigarettes on the human body, as well as literature comparing traditional and electronic smoking. What is more, Farsalinos et al. ${ }^{17}$ showed that cinnamon-flavored liquids have a cytotoxic influence on myoblasts isolated from rats' hearts. Furthermore, Yu et al. ${ }^{18}$ presented findings of changes in the DNA which resulted from e-cigarette aerosol, which were similar to those caused by tobacco smoke.

The effectiveness of nicotine distribution from e-cigarettes seems to be an important factor as well. Research conducted by Eissenberg, ${ }^{19}$ as well as the findings of Vansickel et al. ${ }^{20}$ showed that e-smoking results in a lower nicotine concentration in the blood circulation system, in comparison to traditional smoking. Interesting results have also been presented by Goniewicz et al. ${ }^{21,22}$ Their studies focused on the nicotine concentration in aerosols, as well as on the quantity of nicotine being delivered to the human body while smoking a single traditional cigarette with a determined nicotine amount.

Due to the fact that e-cigarette smoking is a modern issue, the long-term effects are hard to predict. Research concerned with the long-term influence of e-smoking on pulmonary tissues should be conducted. However, there are reports on changes in the blood, ${ }^{23}$ and on subjective symptoms. ${ }^{23,24}$ Furthermore, studies focused on the effects of passive inhaling of e-cigarette aerosols are strongly recommended. The accessible findings are ambiguous.

Table 2. Number and percentage of electronic cigarettes smokers in terms of time

\begin{tabular}{|l|c|c|}
\hline \multicolumn{1}{|c|}{ Number and percentage of students smoked e-cigarettes for: } & Females No (\%) & Males No (\%) \\
\hline $0-6$ months & $26^{\mathrm{a}}(69.44)$ & $13^{\mathrm{b}}(56.00)$ \\
7-12 months & $2(5.56)$ & $4(16.00)$ \\
$1-2$ years & $4(11.11)$ & $4(16.00)$ \\
$2-3$ years & $2(5.56)$ & $3(13.11)$ \\
$3-5$ years & $3(8.33)$ & $3(4.92)$ \\
\hline
\end{tabular}

$\mathrm{p}<0.05$ for $\mathrm{a}-\mathrm{b}$.

Table 3. Reasons for using e-cigarettes

\begin{tabular}{|c|c|c|c|}
\hline The main reasons for using e-cigarettes: & Females No (\%) & Males No (\%) & All No (\%) \\
\hline Trend & 19a (52.78) & $9 b(36.00)$ & $28(45.90)$ \\
\hline Traditional cigarettes disturb ${ }^{1}$ & $5(13.89)$ & $2(8.00)$ & $7(11.48)$ \\
\hline Costs (is cheaper) $)^{2}$ & $2(5.56)$ & $0(0.00)$ & $2(3.28)$ \\
\hline Is permitted in public places ${ }^{3}$ & $3(8.33)$ & $5(20.00)$ & $8(13.1)$ \\
\hline $1 \& 2$ & $1(2.78)$ & $3(12.00)$ & $4(6.56)$ \\
\hline $1 \& 3$ & $0(0.00)$ & $2(8.00)$ & $2(3.28)$ \\
\hline $2 \& 3$ & $1(2.78)$ & $0(0.00)$ & $1(1.64)$ \\
\hline $1 \& 2 \& 3$ & $5(13.89)$ & $4(16.00)$ & $9(14.5)$ \\
\hline As help with quitting (traditional and e-cigarettes): & $11(36.67)$ & $7(33.33)$ & $18(35.29)$ \\
\hline
\end{tabular}

$\mathrm{p}<0.05$ for $\mathrm{a}-\mathrm{b}$. 
Fluoris et al. indicate that nicotine from traditional cigarettes has a comparable influence on passive smokers and the nicotine from e-cigarettes. ${ }^{25}$ Contrarily, Czoguli et al. reported lower nicotine concentrations in the air when using e-cigarettes, compared to traditional ones. ${ }^{26}$

To date, e-cigarette use by teenagers, and even children, is a major concern. A survey conducted by Goniewicz et al. among Polish teenagers between 15 and 19 years old presented a successive increase in the prevalence of e-smoking. ${ }^{4,27}$ The presented study mirrors these findings. Moreover, our research was conducted on a group of dental students, which makes the result even more alarming, as future medical doctors should be aware of the negative influence of nicotine on general health, as well as on the condition of the oral cavity. On this subject, very interesting research about the scale of nicotine use among Polish dentists was presented by Konopka et al. ${ }^{28}$ Their research showed that the prevalence of addiction to nicotine among dentist was $10 \%$ lower compared to the general population, but in relation to other foreign studies, it was an average level.

Furthermore, to date there are no epidemiologic cohort studies on the long-term effects caused by e-cigarettes on the oral cavity tissues or general health condition, as well as comparing them with those caused by traditional cigarettes.

Considering the proven negative effects of nicotine on oral cavity tissues, as well as the inadequacy of evidence of an inoffensive influence of e-cigarettes, the dentists should focus on so-called minimal antinicotine intervention, with an allowance for using e-cigarettes as a shortterm alternative when quitting smoking.

The main reason for taking up electronic cigarettes was the increasing trend. The majority of e-cigarette smokers had been using them for less than 6 months. More than 1 in 3 smokers started using electronic cigarettes with the hope that it would help them quit smoking.

\section{References}

1. Cho JH, Shin NE, Moon SS. Electronic cigarettes smoking experience among adolescents. J Adolesc Health. 2011;49:542-548.

2. Durmowicz EL. The impact of electronic cigarettes on the paediatric population Tob Control. 2014;23:41-46.

3. Goniewicz ML, Gawron M, Nadolska J, Balwicki $Ł$, Sobczak A. Rise in electronic cigarette use among adolescents in Poland. J Adolesc Health. 2014;55:713-715.

4. Goniewicz ML, Zielińska-Danach W. Electronic cigarette use among teenagers and young adults in Poland. Pediatrics, 2012;130:879-885.

5. Moore GF, Littlecott HJ, Moore L. E-cigarette use and intentions to smoke among 10-11-year-old never smokers in Wales. Tob Control. 2014; doi: 10.1136/tobaccocontrol-2014-052011.

6. Bunnell RE, Agaku IT, Arrazola RA. Intentions to smoke cigarettes among never-smoking US middle and high school electronic cigarette users: National Youth Tobacco Survey, 2011-2013. Nicot Tobb Res. 2015;17:228-235.

7. Dockrell M, Morrison R, Bauld L, McNeilli A. E-cigarettes: Prevalence and attitudes in Great Britain. Nicot Tobb Res. 2013;15:1737-1744.

8. Hitchman SC, Brose LS, Brown J, Robson D, McNeilli A. Associations between E-cigarette type, frequency of use, and quitting smoking: findings from a longitudinal online panel survey in Great Britain. Nicot Tobb Res. 2015;17:1187-1194.
9. Vancickel AR, Weaver MF, Eissnberg T. Clinical laboratory assessment of the abuse a liability of an electronic cigarettes. Addiction, 2012;107:1493-1500.

10. Boström L, Bergström J, Dahlen G. Smoking and subgingival microflora in periodontal disease. J Clin Periodontol. 2011;28:212-219.

11. Górska R, Konopka T. Contemporary periodontology. Med. Tour Press International, Otwock, 2013 [in Polish].

12. Górska R. Diagnostic and treatment of oral mucosa diseases. Med. Tour Press International, Otwock, 2011 [in Polish].

13. Apatzidou DA, Riggio MP, Kinane DF. Impact of smoking on the clinical, microbiological and immunological parameters of adult patients with periodontitis. J. Clin Periodontol. 2015;32:973-998.

14. Gomes SC, Piccinin FB, Oppermann RV. Periodontal status in smokers and never-smokers: Clinical findings and real-time polymerase chain reaction quantification of putative periodontal pathogens. J Periodontol. 2006;77:1483-1490.

15. Callahan-Lyon P. Elektronic cigarettes: Human health effects. Tob Control. 2014;23:36-40.

16. Benowitz NL. Emerging nicotine delivery products implication for public health. Ann Am Thoracic Soc. 2014;11:231-235.

17. Farsalinos KE, et al. Comparison of the cytotoxic potential of 24cigarette smoke and electronic cigarette vapor extract on cultured myocardial cells. Int J Environ Res Public Health, 2013;10:5146-5162.

18. $\mathrm{Yu} \mathrm{V}$, et al. Electronic cigarettes induce DNA strand breaks and cell death independently of nicotine in cell lines. Oral Oncol. 2016;52:58-65.

19. Eissenberg T. Electronic nicotine delivery devices: Ineffective nicotine delivery and craving suppression after acute administration. Tob Control. 2010;19:87-88.

20. Vansickel AR, Cobb CO, Weaver MF, Eissenberg TE. A clinical laboratory model for evaluating the acute effects of electronic "cigarettes": nicotine delivery profile and cardiovascular and subjective effects. Cancer Epidemiol Biomarkers Prev. 2010;19:1945-1953.

21. Goniewicz ML, Kuma T, Gawron M, Knysak J, Kosmider L. Nicotine levels in electronic cigarettes. Nicotine Tob Res. 2013;15:158-166.

22. Goniewicz ML, et al. Variations in nicotine yields between single cigarettes. Cent Eur J Public Health. 2012;20:58-61.

23. Farsalinos $\mathrm{K}$, et al. Effect of continuous smoking reduction and abstinence on blood pressure and heart rate in smokers switching to electronic cigarettes. Intern Emerg Med. 2016;11:85-94.

24. Farsalinos K, Romagna G. Chronic idiopathic neutrophilia in a smoker, relieved after smoking cessation with the use of electronic cigarette: a case report. Clin Med Insights Case Rep. 2013;6:15-21.

25 . Flouris $A D$, et al. Acute impact of active and passive electronic cigarette smoking on serum cotinine and lung function. Inhal Toxicol. 2013;25:91-101.

26. Czogala J, Goniewicz ML, Fidelus B, Zielinska-Danch W, Ravers MJ, Sobczak A. Secondhand exposure to vapors from electronic cigarettes. Nicotine Tob Res. 2014;16:655-662.

27. Goniewicz ML, Gawron M, Nadolska J, Balwicki L, Sobczak A. Rise in electronic cigarette use among adolescents in Poland. J Adolesc Health, 2014;55:713-715.

28. Konopka T, Lella A, Stankiewicz-Szałapska A, Zapała J. Tobacco smoking among dentist in Poland. Pol Ann Med. 2017;24:24-30. 